\title{
Exploring socioeconomic inequalities in the use of medicinal herbs among Iranian households: evidence from a national cross-sectional survey
}

\author{
Satar Rezaei ${ }^{1}$, Sina Ahmadi², Amjad Mohamadi-Bolbanabad ${ }^{3}$ and Ahmad Khanijahani ${ }^{4^{*}}$ (1)
}

\begin{abstract}
Background: Association between socioeconomic status and medicinal herbs $(\mathrm{MH})$ are rarely documented in Iran. Our goal was to measure and decompose socioeconomic inequalities in $\mathrm{MH}$ use among Iranian households.

Methods: The data used in this cross-sectional study were extracted from the 2018 Household Income and Expenditure Survey (HIES) $(N=38,859)$. Data on MH use, age, gender, and education status of the head of household; a constructed wealth index of household (as a proxy for household's socioeconomic status); and place of residence (urban or rural) were obtained from the survey. Publicly available province-level data on Human Development Index (HDI) were obtained from the Institute for Management Research at Radbound University. We used the concentration curve and the normalized concentration index $\left(C_{n}\right)$ to measure the magnitude of socioeconomic inequalities in $\mathrm{MH}$ among Iranian households. The $C_{n}$ was decomposed to identify the main determinants of socioeconomic inequalities in $\mathrm{MH}$ in Iran.

Results: The overall prevalence of MH use among Iranian households was 4.7\% (95\% confidence interval [CI]: 4.5 to 4.9\%) in the last month before data collection. The $C_{n}$ for $\mathrm{MH}$ use for the whole of samples was $0.1519 ; 95 \% \mathrm{Cl}=$ 0.1254 to 0.1784 ; suggesting a higher concentration of $\mathrm{MH}$ use among the households with high socioeconomic level. The decomposition analysis indicated that the main contributing factors to the concentration of $\mathrm{MH}$ use were the economic status of households, development status of the province, and education level of the household head.

Conclusions: This study demonstrated that $\mathrm{MH}$ use is more concentrated among socioeconomically advantaged households in Iran and its provinces. This finding might contrast with the widespread belief that wealthy and socioeconomically advantaged populations, compared to low SES groups, tend to seek disproportionately more modern medical treatments and medications than $\mathrm{MH}$. Understanding the factors affecting $\mathrm{MH}$ use, socioeconomic inequality in use of $\mathrm{MH}$ and its determinants provide an opportunity for health policymakers to design effective evidence-based interventions among providers and consumers of $\mathrm{MH}$.
\end{abstract}

Keywords: Medicinal herbs, Complementary and alternative medicine, Inequalities, Socioeconomic status, Iran

\footnotetext{
* Correspondence: khanijahania@duq.edu

${ }^{4}$ Department of Health Administration and Public Health, Rangos School of

Health Sciences, Duquesne University, 600 Forbes Avenue, Pittsburgh, PA

15282, USA

Full list of author information is available at the end of the article
}

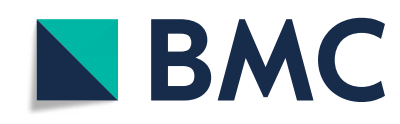

(c) The Author(s). 2020 Open Access This article is licensed under a Creative Commons Attribution 4.0 International License, which permits use, sharing, adaptation, distribution and reproduction in any medium or format, as long as you give appropriate credit to the original author(s) and the source, provide a link to the Creative Commons licence, and indicate if changes were made. The images or other third party material in this article are included in the article's Creative Commons licence, unless indicated otherwise in a credit line to the material. If material is not included in the article's Creative Commons licence and your intended use is not permitted by statutory regulation or exceeds the permitted use, you will need to obtain permission directly from the copyright holder. To view a copy of this licence, visit http://creativecommons.org/licenses/by/4.0/. The Creative Commons Public Domain Dedication waiver (http://creativecommons.org/publicdomain/zero/1.0/) applies to the data made available in this article, unless otherwise stated in a credit line to the data. 


\section{Background}

The use of medicinal herbs $(\mathrm{MH})$ is increasing both in developing and developed countries [1, 2]. As per World Health Organization (WHO) definition, traditional medicine is "the sum total of the knowledge, skill, and practices based on the theories, beliefs, and experiences indigenous to different cultures, whether explicable or not, used in the maintenance of health as well as in the prevention, diagnosis, improvement or treatment of physical and mental illness" [2]. Besides, the term complementary medicine refers to "a broad set of health care practices that are not part of that country's own tradition or conventional medicine and are not fully integrated into the dominant health-care system" [2]. MH is related to a range of medical interventions that are primarily used outside the formal healthcare setting. For millions of people in most countries, especially developing countries, $\mathrm{MH}$ is an important part of health systems and is considered as one of the main sources of health services and, in some cases, are the only sources for care. $\mathrm{MH}$ is usually close to home, accessible, and affordable [3]. The concept of $\mathrm{MH}$ has increasingly gained interest among herbalists and the scientific community worldwide. $\mathrm{MH}$ is defined by the World Health Organization (WHO) as "herbs, herbal materials, herbal preparations and finished herbal products, that contain as active ingredients parts of plants, or plant materials, or combinations thereof" $[2,4]$.

Previous studies report that a high percentage of people worldwide use medicinal to treat various health conditions. Its prevalence ranges from 5 to $90 \%$ in different geographical, social, and cultural settings [5-11]. A systematic review study found that the prevalence of complementary and alternative medicine use varied between 0.3 to $86 \%$ among European Union countries [12]. Stanifer and colleagues (2015) also found that traditional medicine use has increased among all the groups of people, especially those with higher educational attainment and professional occupations, and across all ages in urban and rural residents [13].

Because of the historical background, geographical location, and various climatic conditions, Iran is a habitat of many medicinal plants species. Traditional medicine has always been practiced despite advances in modern medicine [14]. There are more than 7500 plant species in Iran, and about 1800 of those species are considered medicinal [15]. In recent years, $\mathrm{MH}$ has become increasingly popular among Iranians. Hashempur et al. [16] investigated the prevalence of use of complementary and alternative medicine (CAM) in Iranian patients with diabetes mellitus in the Shiraz province. Of the 239 patients included in their study, $75.3 \%$ used at least one type of CAM over the last year.
Existing literature highlights that many factors (e.g., education, income, ethnicity, accessibility, and affordability) affected $\mathrm{MH}$ use in different countries [17-19]. In the case of Iran, most of the studies on $\mathrm{MH}$ use and its main determinants have been focused on specific groups such as pregnant women and those with special health conditions like hypertension, diabetes, HIV, and mental health disorders $[6,11,18,20-22]$. The prevalence of $\mathrm{MH}$ use and its determinants among the general population at the household level is rarely documented. To fill this gap in the current literature, this study aimed to measure and decomposes socioeconomic inequalities in MH use among Iranian households at the national and sub-national levels.

\section{Methods}

Study setting

Iran is a middle-income country located in the Eastern Mediterranean Region (EMR) with an area of 1648 million square kilometers. According to the 2016 census data, Iran's population was approximately 80 million people living in 31 provinces [23]. In the healthcare system in Iran, health care is provided by three sectors, including public, private, and not-for-profit. While the public sector plays a key role in the provision of all three levels of healthcare (i.e., primary, secondary, and tertiary), the private sector mainly provides secondary and tertiary healthcare in urban areas. Non-governmental organizations (NGOs) are active in providing health services for chronic patients, diabetes patients and severe patients, such as cancer patients [24]. MH in Iran are easily available at Atari (an herb store where provide CAM to Iranian people), and the people do not need to visit medical doctors to get prescription.

\section{Data and variables}

The data used in this study was extracted from the 2018 Household Income and Expenditure Survey (HIES) conducted by the Iranian Statistical Center [25]. This is a nationwide cross-sectional survey consisting of face-toface interviews with household heads. Household is the unit of data collection, report, and analysis in the HIES. Households were selected using three-stage cluster sampling. In the first stage, the census areas are classified and selected. The urban and rural blocks are selected in the second stage. In the final stage, households in the sample were selected. Information on sociodemographic characteristics of household (e.g., the age of household head, the gender of household head, and education status of household head); household healthcare utilization (e.g., $\mathrm{MH}$ ); and household assets, income, and expenditure over the past month were collected in the survey. In 2018, data were collected from 38,859 rural and urban households. 
The dichotomous dependent variable of $\mathrm{MH}$ use was constructed using the respondents' answer to if the household used any medicinal herbs (e.g., borage, purgative manna, the manna of Hedysarum, Cichorium, etc.) over the past month. Based on the availability of data in the HIES and previous studies [17-19], we used the gender of household head, age of household head, education status of household head, a constructed wealth index of households (as a proxy for households' socioeconomic status), residential area (urban/rural), and development stats of province based on their HDI score (low, middle, and high) as the determinants of $\mathrm{MH}$ use in households. Province-level data on HDI was accessed from the Institute for Management Research at Radboud University [26]. Principal Component Analysis (PCA) was used to construct a household wealth index [27]. We included the housing characteristics (e.g., rooms per capita, type of house ownership, and house size per square meter) and durable assets of households (e.g., car, TV color, internet, computer/laptop, cell phone, freezer, dishwasher, microwave, vacuum cleaner, motorcycle, and bicycle) in the PCA procedure. Households were classified into five socioeconomic status (SES) groups ranging from the poorest (first quintile) to the richest (fifth quintile) according to the wealth score.

\section{Data analysis}

\section{Measuring socioeconomic inequalities in the use of medicinal herbs}

We used Concentration index $(\mathrm{C})$ and Concentration curve [28] to examine and quantify the socioeconomicrelated inequalities in $\mathrm{MH}$ use among households in Iran and its provinces. In the Concentration curve, the cumulative proportion of households ranked by SES and the cumulative proportion of $\mathrm{MH}$ use are plotted on $\mathrm{x}$ and $\mathrm{y}$ axes, respectively. If the concentration curve lies above the 45-degree line. This suggests that $\mathrm{MH}$ use is concentrated more among poor households and vice versa. The $C$ takes a value between -1 and +1 , with the value of zero meaning no socioeconomic-related inequalities. A negative sign of the $\mathrm{C}$ indicates that $\mathrm{MH}$ use is more concentrated among households with low SES and vice versa. AS the MH use is a binary (is either 0 or 1 ) measure, and the estimated $C$ is not between -1 and +1 . Thus, as suggested by Wagstaff [29], we normalized the Concentration index $\left(C_{n}\right)$ by dividing it by $\frac{1}{1-\mu}$, where $\mu$ is the mean of the use of $\mathrm{MH}$.

\section{Decomposing socioeconomic inequalities in the use of medicinal herbs}

We used the decomposition methods to identify the main factors associated with the observed socioeconomicrelated inequalities in use of $\mathrm{MH}$. In the decomposition analysis, a set of $\mathrm{k}$ explanatory factors, $\mathrm{x}_{\mathrm{k}}$, were regressed on the outcome variable, y (here use of $\mathrm{MH}$ ) in a linear regression model as follows:

$$
\mathrm{y}=\alpha+\sum_{\mathrm{k}} \beta_{\mathrm{k}} \mathrm{x}_{\mathrm{k}}+\varepsilon
$$

The $\mathrm{C}$ for $\mathrm{MH}$ use can be decomposed using the followng equation [30]:

$$
C=\sum_{k}\left(\frac{\beta_{k} \bar{x}_{k}}{\mu}\right) C_{k}+\frac{G_{\varepsilon}}{\mu} .
$$

Where $\overline{\mathrm{x}}_{\mathrm{k}}$ is the mean of $\mathrm{x}_{\mathrm{k}}, \mu$ presents the mean of use of $M H, C_{k}$ shows the $C$ for $x_{k}$, and $\left(\frac{\beta_{k} \bar{x}_{k}}{\mu}\right) C_{k}$ is the elasticity of $\mathrm{MH}$ use with respect to the $\mathrm{x}_{\mathrm{k}}$. A positive (negative) elasticity for a factor shows that the probability of $\mathrm{MH}$ use among households increasing (decreasing) when the value of that factor also increases (decreases). $\sum_{k}\left(\frac{\beta_{k} \bar{x}_{k}}{\mu}\right) C_{k}$ denotes the contribution of explanatory factors, $\mathrm{x}_{\mathrm{k}}$, to the overall $\mathrm{C}$ for the use of $\mathrm{MH}$. The last term, $\frac{\mathrm{GC}_{\varepsilon}}{\mu}$, is the residuals part and indicates the portion of the $\mathrm{C}$ for use of $\mathrm{MH}$ that cannot be explained by the explanatory variables included in the analysis.

Wagstaff et al. [29] showed that the Cn can be decomposed to its determinants using the following formula:

$$
C_{n}=\frac{C}{1-\mu}=\frac{\sum_{k}\left(\frac{\beta_{k} \bar{x}_{k}}{\mu}\right) C_{k}}{1-\mu}+\frac{\frac{A C_{\varepsilon}}{\mu}}{1-\mu}
$$

A negative absolute contribution for each factor to the $\mathrm{C}_{\mathrm{n}}$ shows that the socioeconomic distribution of the respective factor and its association with $\mathrm{MH}$ use leads to lower $\mathrm{MH}$ use among the poorest households. To calculate the relative contribution of each factor, we divided the absolute contribution of that factor by the $C_{n}$ and then multiply by 100 . As $\mathrm{MH}$ use is a binary variable, we used the non-linear logit regression to obtain the marginal effect of determinants. All the analyses were performed using Stata Version 14. To ensure proper point and variance estimations, survey design weights and parameters were incorporated in the analyses. $P$-values less than 0.05 considered statistically significant. The geographical map was produced by ArcGIS software Version 10.6.1.

\section{Results}

\section{Descriptive statistics}

The descriptive characteristics of the 38,859 households included in this study are presented in Table 1. Of these, $86.7 \%(n=33,752)$ of household heads were male. The mean age of the household heads was 50.4 years (standard deviation $[\mathrm{SD}]=15.6) .76 \%(n=29,524)$ of household 
Table 1 Characteristics of the households included in the study $(N=38,859)$

\begin{tabular}{|c|c|c|c|}
\hline Variables & $\begin{array}{l}\mathrm{n}(\%) \\
(\mathrm{N}=38,859)\end{array}$ & $\begin{array}{l}\text { Used Herbal Medicine } n(\%) \\
(N=1829)\end{array}$ & $\begin{array}{l}\text { Did not use Herbal Medicine } n(\%) \\
(N=37,030)\end{array}$ \\
\hline \multicolumn{4}{|l|}{ Demographic variables } \\
\hline \multicolumn{4}{|l|}{ Sex of household head } \\
\hline Male & $33,752(86.9)$ & $1619(4.8)$ & $32,133(95.2)$ \\
\hline Female & $5107(13.1)$ & $210(4.1)$ & $4897(95.9)$ \\
\hline \multicolumn{4}{|l|}{ Age of household head } \\
\hline $15-45$ & $16,981(43.7)$ & $802(4.7)$ & $16,179(95.3)$ \\
\hline $46-65$ & $14,731(37.9)$ & $715(4.8)$ & $14,016(95.2)$ \\
\hline 66 and above & $7147(18.4)$ & $312(4.4)$ & 6835 (95.6) \\
\hline \multicolumn{4}{|l|}{ Socioeconomic variables } \\
\hline \multicolumn{4}{|c|}{ Education status of household head } \\
\hline Illiterate & $9335(24.0)$ & $353(3.8)$ & $8982(96.2)$ \\
\hline Primary school & $10,808(27.8)$ & $459(4.3)$ & $1349(95.7)$ \\
\hline Secondary school & $6965(17.9)$ & $325(4.7)$ & $6640(95.3)$ \\
\hline High school & 7705 (19.8) & $420(5.4)$ & 7285 (94.6) \\
\hline Academic degree & $4046(10.4)$ & $272(6.7)$ & $3774(93.3)$ \\
\hline \multicolumn{4}{|c|}{ Wealth index of households } \\
\hline Poorest & $7730(19.9)$ & $211(2.7)$ & 7519 (97.3) \\
\hline Poor & $7775(20.0)$ & $318(4.1)$ & 7457 (95.9) \\
\hline Middle & 7779 (20.0) & $371(4.8)$ & 7408 (95.2) \\
\hline Rich & $7785(20.0)$ & $450(5.8)$ & 7335 (94.2) \\
\hline Richest & $7790(20.1)$ & $479(6.2)$ & $7311(93.8)$ \\
\hline \multicolumn{4}{|l|}{ Ecological variables } \\
\hline \multicolumn{4}{|l|}{ Geographical area } \\
\hline Urban & $20,313(52.3)$ & $1077(5.3)$ & $19,236(94.7)$ \\
\hline Rural & $18,546(47.7)$ & $752(4.1)$ & $17,794(95.9)$ \\
\hline \multicolumn{4}{|c|}{ Province category based on HDI } \\
\hline Low & $14,050(36.2)$ & $407(2.9)$ & $13,643(97.1)$ \\
\hline Middle & $12,716(32.7)$ & $613(4.8)$ & $12,103(95.2)$ \\
\hline High & $12,093(31.1)$ & $809(6.7)$ & $11,284(93.3)$ \\
\hline
\end{tabular}

$\mathrm{HDI}$ is the human development index

heads were literate, and $88.4 \%(n=34,370)$ of the study population had health insurance coverage. The overall prevalence of $\mathrm{MH}$ use over the past month among the households was $4.7 \%$ (95\% confidence interval [CI]: 4.5 to $4.9 \%)$. The prevalence of $\mathrm{MH}$ use was $2.7 \%$ (95\% CI: 2.4 to $3.1 \%$ ) and $6.1 \%$ (95\% CI: 5.6 to $6.7 \%$ ) among the poorest and richest households, respectively. This figure for urban and rural households was 5.3\% (95\% CI: 5.0 to $5.6 \%$ ) and $4.0 \%$ (95\% CI: 3.8 to $4.4 \%$ ), respectively. The prevalence of $\mathrm{MH}$ use among households across 31 provinces of Iran is demonstrated in Fig. 1. There are disparities in $\mathrm{MH}$ use across the provinces of Iran. The prevalence of $\mathrm{MH}$ usage in Lorestan and Fars provinces were 0.2 and $16.5 \%$, respectively, representing the lowest and highest prevalence of $\mathrm{MH}$ use.

\section{Multivariate logistic regression analysis}

The results of logistic regression to identify the main factors affecting $\mathrm{MH}$ among households in Iran are reported in Table 2. Rural households are less likely to use $\mathrm{MH}$ than their urban counterparts. Additionally, odds ratios greater than one indicates that, compared to the reference groups, households with higher socioeconomic status and provinces with higher HDI were more likely to use $\mathrm{MH}$.

Table 3 shows the $C_{n}$ for $\mathrm{MH}$ use among households for the whole of samples, rural and urban areas. The positive value of the $C_{n}$ suggested that $\mathrm{MH}$ use is more prevalent among better-off households $\left(C_{n}=0.1519\right.$; $95 \% \mathrm{CI}=0.1254$ to 0.1784$)$. This finding was confirmed in both urban $\left(C_{n}=0.1754 ; 95 \% \mathrm{CI}=0.1408\right.$ to 0.2101$)$ 


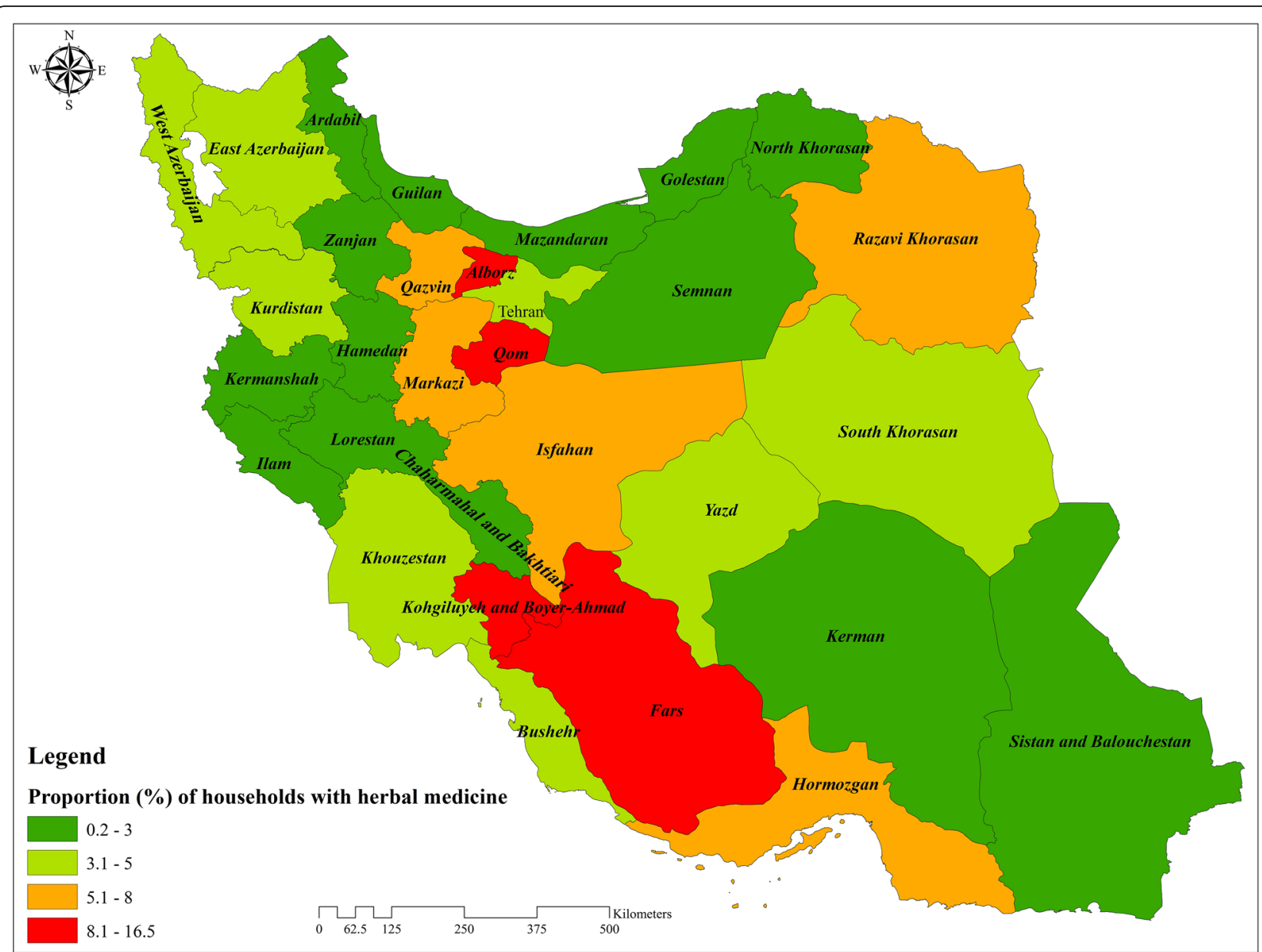

Fig. 1 Proportion of households with use of medicinal herbs over the last month across provinces in Iran, 2018 (developed by the authors using ArcGIS Desktop version 10.6.1)

and rural $\left(C_{n}=0.1191 ; 95 \% \mathrm{CI}=0.0779\right.$ to 0.1603$)$ households. As indicated in Fig. 2, the concentration curve for $\mathrm{MH}$ use for the whole sample lies below the 45-degree line, suggesting that $\mathrm{MH}$ use over the past month was more concentrated among richer households.

Figure 3 shows the $C_{n}$ in $\mathrm{MH}$ use across provinces in Iran. While $\mathrm{MH}$ use was found to be concentrated among the poor households in the Bushehr and Kohgiluyeh Buyer Ahmad provinces, a higher concentration of MH usage was found among the rich households in the other 29 provinces.

\section{Determinants of socioeconomic inequalities in $\mathrm{MH}$ use}

The results of the decomposition analysis on socioeconomic inequalities in $\mathrm{MH}$ use among Iranian households are reported in Table 4. Our findings indicate that the probability of $\mathrm{MH}$ use was higher in rural households (see the second column of
Table 4; marginal effect). We also found that the probability of $\mathrm{MH}$ usage among the wealthiest households was $1.7 \%$ higher as compared to the poorest households. Based on the results of $C_{x}$ of explanatory variables, female-headed households, illiterate-headed households, and older household heads were relatively poor. In addition, households living in rural areas were relatively rich as compared with that's ones.

The fifth and sixth columns of Table 4 show the absolute and percentage contribution of explanatory variables to the socioeconomic-related inequalities in $\mathrm{MH}$ use. According to the results of the decomposition analysis, the main contributing factors to the concentration of $\mathrm{MH}$ usage among the socioeconomically advantaged households in Iran were the economic status of households (48.2\%), development status of the province $(20.7 \%)$, and educational attainment of the household head (7.1\%). 
Table 2 Results of bivariate and multivariate logistic regression

\begin{tabular}{|c|c|c|}
\hline Variables & Crude OR $(95 \% \mathrm{Cl})$ & Adjusted OR (95\% \\
\hline \multicolumn{3}{|l|}{ Demographic variables } \\
\hline \multicolumn{3}{|l|}{ Sex of household head } \\
\hline Male (ref.) & 1 & 1 \\
\hline Female & $0.89(0.72$ to 1.10$)$ & 1.05 (0.83 to 1.32$)$ \\
\hline \multicolumn{3}{|l|}{ Age of household head } \\
\hline $15-45$ (ref.) & 1 & 1 \\
\hline $46-65$ & $1.00(0.85$ to 1.18$)$ & $0.96(0.80$ to 1.15$)$ \\
\hline 66 and above & $0.90(0.73$ to 1.10$)$ & 0.98 (0.78 to 1.24$)$ \\
\hline \multicolumn{3}{|l|}{ Socioeconomic variables } \\
\hline \multicolumn{3}{|c|}{ Education status of household head } \\
\hline Illiterate (ref.) & 1 & 1 \\
\hline Primary school & $1.30(1.04$ to 1.63$)$ & 1.12 (0.87 to 1.44$)$ \\
\hline Secondary school & $1.32(1.06$ to 1.65$)$ & $1.05(0.81$ to 1.37$)$ \\
\hline High school & $1.80(1.44$ to 2.25$)$ & 1.30 (0.98 to 1.72$)$ \\
\hline Academic degree & 1.84 (1.43 to 2.38$)$ & 1.27 (0.91 to 1.77$)$ \\
\hline \multicolumn{3}{|c|}{ Wealth index of households } \\
\hline Poorest (ref.) & 1 & 1 \\
\hline Poor & $1.48(1.12$ to 1.96$)$ & 1.31 (0.98 to 1.75$)$ \\
\hline Middle & 1.83 (1.39 to 2.43 ) & 1.52 (1.13 to 2.04$)$ \\
\hline Rich & 2.04 (1.55 to 2.68$)$ & 1.60 (1.18 to 2.17$)$ \\
\hline Richest & 2.15 (1.64 to 2.84$)$ & $1.60(1.16$ to 2.20$)$ \\
\hline \multicolumn{3}{|l|}{ Ecological variables } \\
\hline \multicolumn{3}{|l|}{ Geographical area } \\
\hline Urban (ref.) & 1 & 1 \\
\hline Rural & 0.59 (0.50 to 0.69$)$ & 0.73 (0.63 to 0.87 ) \\
\hline \multicolumn{3}{|c|}{ Province category based on HDI } \\
\hline Low (ref.) & 1 & 1 \\
\hline Middle & $1.33(1.08$ to 1.63$)$ & $1.23(1.02$ to 1.51$)$ \\
\hline High & 2.19 (1.78 to 2.68$)$ & 1.83 (1.48 to 2.27$)$ \\
\hline
\end{tabular}

$\mathrm{OR}$ is odds ratio and $\mathrm{HDI}$ is the human development index

Crude OR represents the odds ratio in a bivariate model with a

single predictor

Adjusted OR represents odds ratios in the multivariate model with all predictors entered simultaneously into the model

Of the total socioeconomic-related inequalities in $\mathrm{MH}$ use, $68.3 \%$ was explained by the factors included in the analysis. The remaining $31.7 \%$ of the observed inequalities in $\mathrm{MH}$ is explained by other variables, such as ethnicity and health condition, that are not included in the model.

Table 3 The normalized concentration indices for $\mathrm{MH}$ use for whole sample, and rural and urban areas in Iran

\begin{tabular}{llll}
\hline Sample & $\mathbf{n}$ & The $\boldsymbol{C}_{\boldsymbol{n}}$ & $\mathbf{9 5 \%}$ Confidence interval \\
\hline Urban & 20,313 & 0.1754 & 0.1408 to 0.2101 \\
Rural & 18,546 & 0.1191 & 0.0779 to 0.1603 \\
Total & 38,859 & 0.1519 & 0.1254 to 0.1784 \\
\hline
\end{tabular}

$\mathrm{Cn}$ is the normalized relative concentration index
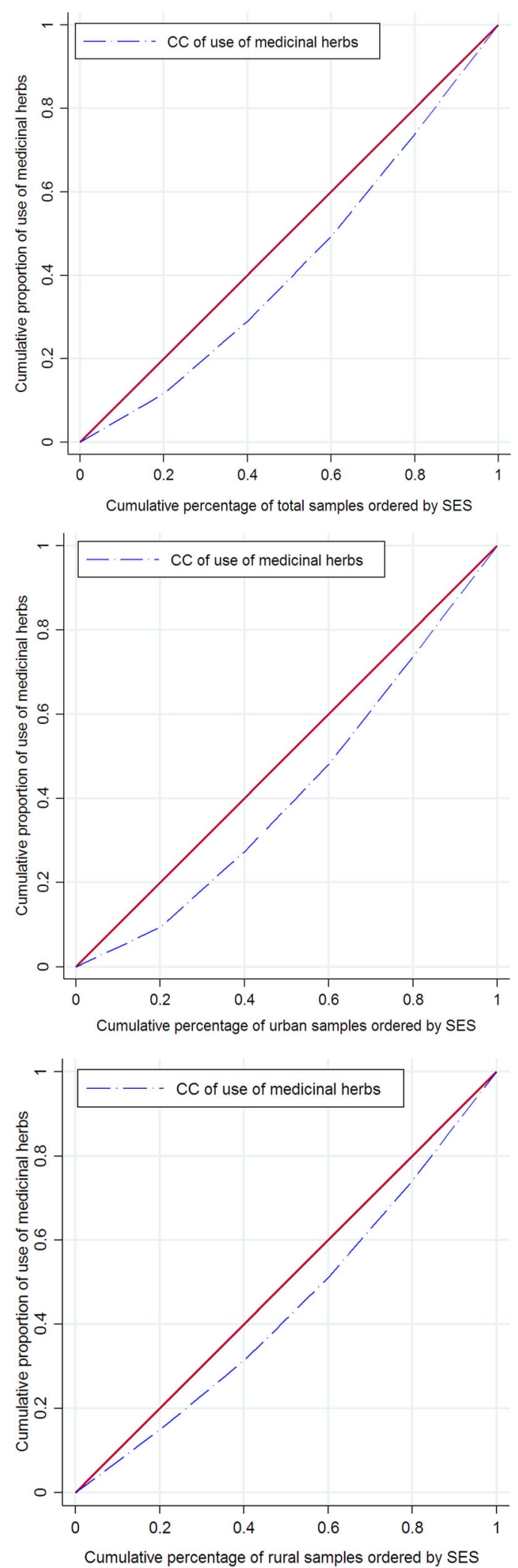

Fig. 2 The Concentration curve for herbal medicine usage for whole sample, rural and urban areas, 2018 


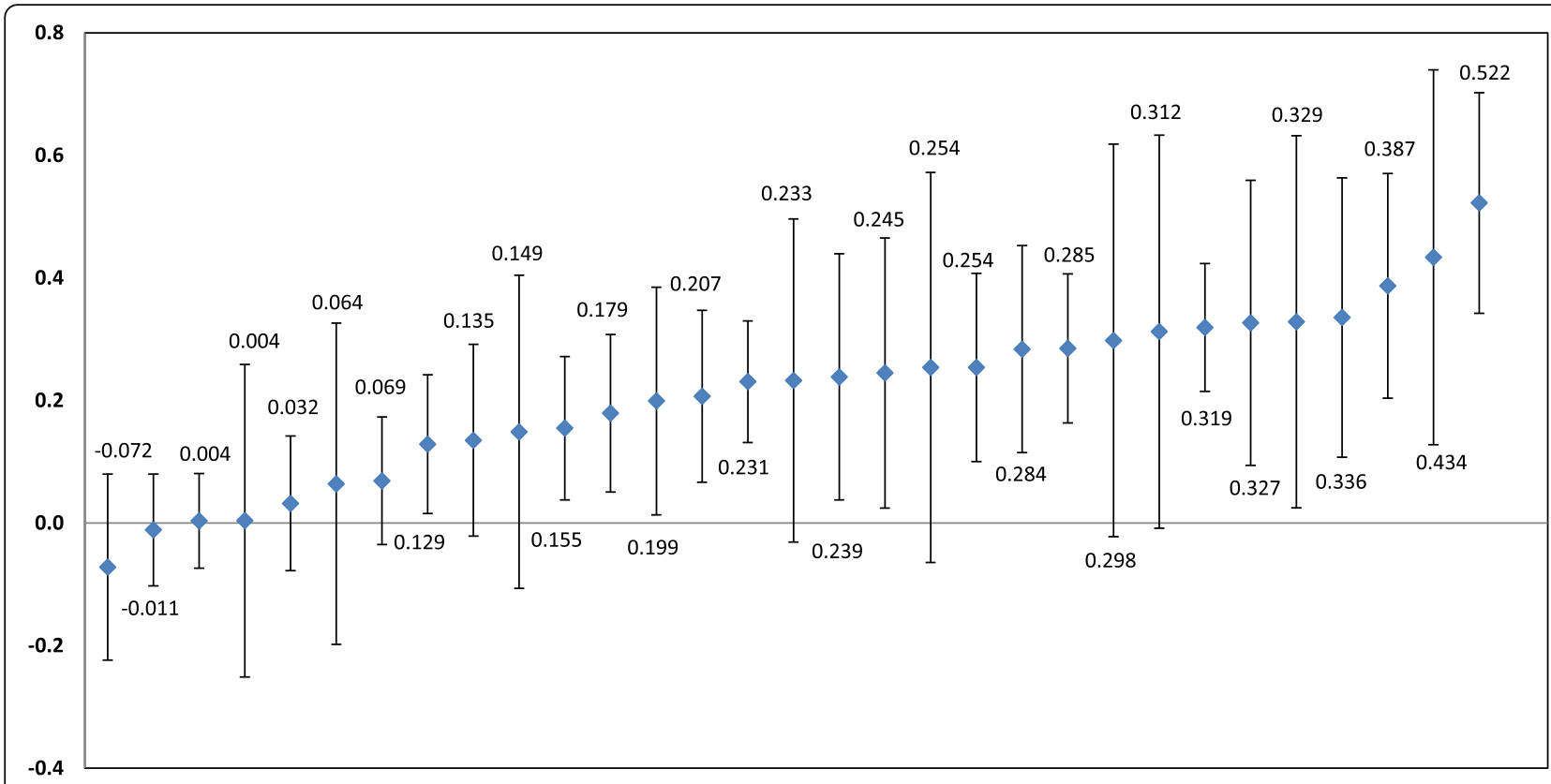

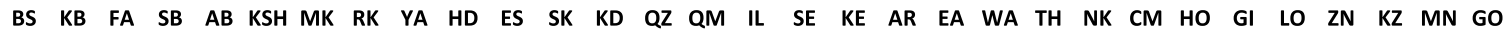

Fig. 3 The normalized concentration index (Cn) for use of Herbal medicine across Iranian provinces, 2018

\section{Discussion}

The use of medicinal herbs as a self-care strategy is a major part of health systems in a majority of countries. In some cases, it is also the only source of care for many people. $\mathrm{MH}$ use is increasing, and its role in individual health is well-established [3]. While there is some evidence on the prevalence of $\mathrm{MH}$ use and its key determinants in Iran, there is no information on socioeconomic-related inequalities in $\mathrm{MH}$ use at the national and sub-national levels. This study was designed to measure the extent of socioeconomic inequalities in MH use across Iran's provinces. Furthermore, the observed socioeconomic inequalities in $\mathrm{MH}$ use were decomposed to find the important determinates of these inequalities among Iranian households.

According to the finding of this study, the overall prevalence of $\mathrm{MH}$ use over the past month among the households was $4.7 \%$ (95\% CI: 4.5-4.9\%). The magnitude of $\mathrm{MH}$ use in this study is lower than studies done in other countries $[1,6,9]$. Deanne and colleagues reported that $63.5 \%$ of AIDS patients in Uganda had used $\mathrm{MH}$ after HIV diagnosis [22]. Results of a systematic review study in sub-Saharan Africa show that MH was the most common type of CAM that is used by patients, the prevalence of which was 25-65\% [11]. These differences in the $\mathrm{MH}$ use might be explained by study population characteristics and the cultural and developmental differences among countries. In the present study, $\mathrm{MH}$ use was studied among the general population, but previous studies have mainly focused on populations with specific health conditions such as hypertension, diabetics, and HIV [6, 11, 18, 20-22].

The prevalence of $\mathrm{MH}$ had a considerable diversity across provinces, varying from 0.2 to $16.5 \%$. This variation might be due to the socio-demographic composition of communities, climate diversity, cultural identities, and differences in beliefs. While the prevalence of $\mathrm{MH}$ in the Lorestan province was lowest, the use of it in the Fars province was higher than in other provinces. Climatic variations in the Fars province creates an opportunity for an extensive range of plants from diverse families to grow, and this determinant has had the most for the province to turn to the largest medicinal plants of the country [15]. The results showed that $\mathrm{MH}$ use was more concentrated among individuals with high SES. This finding can be explained by the fact that higher SES individuals can afford to buy medicinal herbs due to their higher ability to pay. This observation is consistent with previous studies, in which affordability is one of the most important factors for $\mathrm{MH}$ usage [17-19, 31, 32]. A study on the use of herbal medicine in Taiwan indicated that CHM use among pregnant women with a higher level of education and larger income had greater rates of CHM usage [33]. Additionally, a higher concentration in $\mathrm{MH}$ use in higher SES households is also found in both urban and rural regions. Our decomposition analysis revealed that the SES of households and residing province are the main contributing factors to 
Table 4 Decomposition of socioeconomic inequalities in MH use among Iranian households

\begin{tabular}{|c|c|c|c|c|c|c|}
\hline & \multirow{2}{*}{$\begin{array}{l}\text { Marginal } \\
\text { effect }\end{array}$} & \multirow[t]{2}{*}{ Elasticity } & \multirow[t]{2}{*}{$C_{x}$} & \multicolumn{3}{|c|}{ Contribution to the $C_{n}$} \\
\hline & & & & Contribution & $\%$ & Summed\% \\
\hline \multicolumn{7}{|l|}{ Demographic variables } \\
\hline \multicolumn{7}{|l|}{ Sex of household head } \\
\hline \multicolumn{7}{|l|}{ Male (ref.) } \\
\hline Female & 0.0006 & 0.0016 & -0.3057 & -0.0005 & -0.3 & -0.3 \\
\hline \multicolumn{7}{|l|}{ Age of household head } \\
\hline \multicolumn{7}{|l|}{$15-45$ (ref.) } \\
\hline $46-65$ & 0.0002 & 0.0015 & 0.0855 & 0.0001 & 0.1 & \\
\hline 66 and above & 0.0016 & 0.0064 & -0.1626 & -0.0011 & -0.7 & -0.6 \\
\hline \multicolumn{7}{|l|}{ Socioeconomic variables } \\
\hline \multicolumn{7}{|c|}{ Education status of household head } \\
\hline \multicolumn{7}{|l|}{ Illiterate (ref.) } \\
\hline Primary school & 0.0052 & 0.0141 & -0.0260 & -0.0004 & -0.3 & \\
\hline Secondary school & 0.0024 & 0.0488 & 0.0458 & 0.0023 & 1.5 & \\
\hline High school & 0.0128 & 0.0492 & 0.1699 & 0.0088 & 5.8 & \\
\hline Academic degree & 0.0117 & 0.0000 & 0.2844 & 0.0000 & 0.0 & 7.1 \\
\hline \multicolumn{7}{|c|}{ Wealth index of households } \\
\hline \multicolumn{7}{|l|}{ Poorest (ref.) } \\
\hline Poor & 0.0092 & 0.0393 & -0.4021 & -0.0166 & -10.9 & \\
\hline Middle & 0.0121 & 0.0515 & -0.0018 & -0.0001 & -0.1 & \\
\hline Rich & 0.0160 & 0.0678 & 0.3987 & 0.0284 & 18.7 & \\
\hline Richest & 0.0172 & 0.0733 & 0.7996 & 0.0615 & 40.5 & 48.2 \\
\hline \multicolumn{7}{|l|}{ Ecological variables } \\
\hline \multicolumn{7}{|l|}{ Geographical area } \\
\hline \multicolumn{7}{|l|}{ Urban (ref.) } \\
\hline Rural & -0.0103 & -0.1042 & 0.0943 & -0.0103 & -6.8 & -6.7 \\
\hline \multicolumn{7}{|c|}{ Province category based on HDI } \\
\hline \multicolumn{7}{|l|}{ Low (ref.) } \\
\hline Middle & 0.0082 & 0.0570 & -0.0296 & -0.0018 & -1.2 & \\
\hline High & 0.0290 & 0.1917 & 0.1654 & 0.0333 & 21.9 & 20.7 \\
\hline Sum & & & & 0.1037 & & 68.3 \\
\hline Residuals & & & & 0.0482 & & 31.7 \\
\hline The $C_{n}$ & & & & 0.1519 & & 100.0 \\
\hline
\end{tabular}

the concentration of $\mathrm{MH}$ among the more advantaged households in Iran.

Although $\mathrm{MH}$ was used by people of all incomes in both urban and rural settings, our study indicated that the prevalence of $\mathrm{MH}$ was higher in female-headed households, households with older age, illiterate-headed households, and urban households. Female-headed households were noted to use $\mathrm{MH}$ more frequently than male-headed households. Consistent with our results, Geissler and colleagues found that with increasing age, females relied more heavily on $\mathrm{MH}$ than males [34].
Also, the lower educational level was found to be associated with a higher probability of $\mathrm{MH}$ use in Nigeria [35].

Our analysis indicated that there is a positive association between the age of household head and $\mathrm{MH}$ use, which is consistent with studies conducted by Aboyade et al. [36] in South Africa, Ching et al. [37] in Malaysia, and Chung-Hsuen Cohen et al. in the US [38]. The prevalence of $\mathrm{MH}$ usage was higher among residents in urban than in rural areas. This difference in herbal use can be potentially explained by the ease of access to drug shops and pharmacies that sell herbal medicine in urban 
areas. Evidence from previous studies shows that pharmacy and drug-shop can facilitate the use of alternative and complementary medicine [39]. Additionally, previous studies showed that urban dwellers were more likely to seek healthcare than their rural residents $[36,40]$.

Several limitations of this must be acknowledged. First, the cross-sectional design did not allow us to extract causal conclusions between $\mathrm{MH}$ usage and other factors. Second, the study utilized self-reported measures; thus there is a potential for recall bias in reporting the use of any herbal medicine over the past month. Despite these limitations inherent to survey data, findings extend knowledge of inequalities in $\mathrm{MH}$ use because we use data from nationally representative surveys.

\section{Conclusions}

This study demonstrated that MH use is more concentrated among households with high SES in Iran and its provinces. Urban households, households with high socioeconomic status, female-headed households, and households headed by older people were more likely to use medicinal herbs. This finding might be in contrast with the popular belief that wealthy and socioeconomically advantaged populations, compared to low SES groups, tend to seek disproportionately more modern medical treatments and medications than $\mathrm{MH}$. Understanding the factors affecting $\mathrm{MH}$ use, socioeconomic inequality in the use of $\mathrm{MH}$ and its determinants provide an opportunity for health policymakers to design effective evidence-based interventions among providers and consumers of $\mathrm{MH}$.

\section{Abbreviations}

$\mathrm{MH}$ : Medicinal herbs; HIES: Household Income and Expenditure Survey; PCA: Principal component analysis; $C_{n}$ : Normalized concentration index; SES: Socioeconomic status

\section{Acknowledgements}

Not applicable.

\section{Authors' contributions}

All authors contributed to the conception and design of the study. SR and AK performed the data analysis. SR, SA and AMB drafted the manuscript. AK critically revised the manuscript for important intellectual content. All authors read and approved the final manuscript.

\section{Funding}

This study was funded by Kurdistan University of Medical Sciences. The Funder had no role in the design of the study and collection, analysis, interpretation of data and in writing the manuscript.

\section{Availability of data and materials}

The data used in the study was extracted from the Household Income and Expenditure Surveys (HIESs) collected by the Iranian Statistical Center [41]. The HIES are can be accessed from https://www.amar.org.ir/english/Statisticsby-Topic/Household-Expenditure-and-Income\#2220530-releases.

\section{Ethics approval and consent to participate}

The study was approved by the Ethics Review Committee of the Deputy of Research at Kurdistan University of Medical Sciences (IR.MUK.REC.1899.027).
Consent for publication

Not applicable.

\section{Competing interests}

The authors declare no competing interests.

\section{Author details}

${ }^{1}$ Research Center for Environmental Determinants of Health, Health Institute, Kermanshah University of Medical Sciences, Kermanshah, Iran. ${ }^{2}$ Department of Social Welfare Management, University of Social Welfare and

Rehabilitation Sciences, Tehran, Iran. ${ }^{3}$ Social Determinants of Health Research Center, Research Institute for Health Development, Kurdistan University of Medical Sciences, Sanandaj, Iran. ${ }^{4}$ Department of Health Administration and Public Health, Rangos School of Health Sciences, Duquesne University, 600 Forbes Avenue, Pittsburgh, PA 15282, USA.

Received: 8 February 2020 Accepted: 23 October 2020

Published online: 09 November 2020

\section{References}

1. Frass M, Strassl RP, Friehs H, Müllner M, Kundi M, Kaye AD. Use and acceptance of complementary and alternative medicine among the general population and medical personnel: a systematic review. Ochsner J. 2012; 12(1):45-56.

2. Organization WH. WHO global report on traditional and complementary medicine 2019: World Health Organization; 2019.

3. Qi Z. WHO traditional Medicine strategy. 2014-2023. Geneva: World Health Organization; 2013.

4. Bodeker G, Ong C-K. WHO global atlas of traditional, complementary and alternative medicine: World Health Organization; 2005.

5. Asfaw Erku D, Basazn Mekuria A. Prevalence and correlates of complementary and alternative medicine use among hypertensive patients in Gondar town, Ethiopia. Evid Based Complement Alternat Med. 2016;2016: 6987636.

6. Brahmi SA, El M'rabet FZ, Benbrahim Z, Akesbi Y, Amine B, Nejjari C, et al. Complementary medicine use among Moroccan patients with cancer: a descriptive study. Pan Afr Med J. 2011;10:36.

7. Behnood-Rod A, Khoshkbejari MAP, Pourzargar P, Hassanzadeh M, Moharamzad Y, Foroughi F. Complementary and alternative medicine use among Iranian patients attending urban outpatient general practices. Complement Ther Clin Pract. 2018;30:58-63.

8. Oreagba IA, Oshikoya KA, Amachree M. Herbal medicine use among urban residents in Lagos, Nigeria. BMC Complement Altern Med. 2011:11(1):117.

9. Ekor M. The growing use of herbal medicines: issues relating to adverse reactions and challenges in monitoring safety. Front Pharmacol. 2014;4:177.

10. John LJ, Shantakumari N. Herbal medicines use during pregnancy: a review from the Middle East. Oman Med J. 2015:30(4):229.

11. Liwa AC, Smart LR, Frumkin A, Epstein H-AB, Fitzgerald DW, Peck RN. Traditional herbal medicine use among hypertensive patients in subSaharan Africa: a systematic review. Curr Hypertens Rep. 2014;16(6):437.

12. Eardley S, Bishop FL, Prescott P, Cardini F, Brinkhaus B, Santos-Rey K, et al. A systematic literature review of complementary and alternative medicine prevalence in EU. Complement Med Res. 2012;19(Suppl. 2):18-28.

13. Stanifer JW, Patel UD, Karia F, Thielman N, Maro V, Shimbi D, et al. The determinants of traditional medicine use in northern Tanzania: a mixedmethods study. PLoS One. 2015;10(4):e0122638.

14. Owfi RE, Safaian N. Overview of important medicinal plants at Fars Province, Iran. Med Aromat Plants. 2017:6:298.

15. Adhami H-R, Mesgarpour B, Farsam H. Herbal Medicine in Iran. HerbalGram. 2007;74:34-43.

16. Hashempur MH, Heydari M, Mosavat SH, Heydari ST, Shams M. Complementary and alternative medicine use in Iranian patients with diabetes mellitus. J Integr Med. 2015;13(5):319-25.

17. Misawa J, Ichikawa R, Shibuya A, Maeda Y, Hishiki T, Kondo Y. Social determinants affecting the use of complementary and alternative medicine in Japan: An analysis using the conceptual framework of social determinants of health. PLoS One. 2018;13(7):e0200578.

18. Chao MT, Wade CM. Socioeconomic factors and women's use of complementary and alternative medicine in four racial/ethnic groups. Ethn Dis. 2008;18(1):65 
19. Ganasegeran K, Rajendran AK, Al-Dubai SAR. Psycho-socioeconomic factors affecting complementary and alternative medicine use among selected rural communities in Malaysia: a cross-sectional study. PLoS One. 2014;9(11):e112124.

20. Abdullahi AA. Trends and challenges of traditional medicine in Africa. Afr J Tradit Complement Altern Med. 2011;8(5S):115-23.

21. Laelago T, Yohannes T, Lemango F. Prevalence of herbal medicine use and associated factors among pregnant women attending antenatal care at public health facilities in Hossana Town, Southern Ethiopia: facility based cross sectional study. Arch Public Health. 2016;74(1):7.

22. Langlois-Klassen D, Kipp W, Jhangri GS, Rubaale T. Use of traditional herbal medicine by AIDS patients in Kabarole District, western Uganda. The American journal of tropical medicine and hygiene. Am J Trop Med Hyg. 2007;77(4):757-63.

23. Statistical Center of Iran: Population and Housing Censuses 2016. 2020. https://www.amar.org.ir/english/Population-and-Housing-Censuses. Accessed 6 Feb 2020.

24. Mehrdad R. Health system in Iran. JMAJ. 2009;52(1):69-73.

25. Statistical Center of Iran: Statistics by Topic: Household, Expenditure and Income 2010. 2020. https:/www.amar.org.ir/english/Statistics-by-Topic/HouseholdExpenditure-and-Income\#287686-statistical-survey. Accessed 6 Feb 2020.

26. Institute for Management Research: Subnational Human Development Index (3.0). 2017. https://globaldatalab.org/shdi/. Accessed 6 Feb 2020

27. Vyas S, Kumaranayake L. Constructing socio-economic status indices: how to use principal components analysis. Health Policy Plan. 2006;21(6):459-68.

28. O'Donnell O, O'Neill S, Van Ourti T, Walsh B. Conindex: estimation of concentration indices. Stata J. 2016;16(1):112-38.

29. Wagstaff A. The concentration index of a binary outcome revisited. Health Econ. 2011;20(10):1155-60.

30. Wagstaff A, van Doorslaer E, Watanabe N. On decomposing the causes of health sector inequalities with an application to malnutrition inequalities in Vietnam: The World Bank; 2001.

31. Chung VC, Wong SY, Wang HH, Wong MC, Wei X, Wang J, et al. Use of traditional and complementary medicine as self-care strategies in community health centers: cross-sectional study in urban pearl river delta region of china. Medicine (Baltimore). 2016;95(23):e3761.

32. Kuunibe N, Domanban PB. Demand for complementary and alternative medicine in Ghana. Int J Humanit Soc Sci. 2012;2:288-94.

33. Wen S-H, Chang W-C, Shen H-S, Wu H-C. Prescription patterns and factors influencing the use of Chinese herbal medicine among pregnant women in Taiwan: a population-based retrospective study. BMC Complement Med Ther. 2020;20(1):240

34. Geissler PW, Nokes K, Prince RJ, Achieng'Odhiambo R, Aagaard-Hansen J, Ouma JH. Children and medicines: self-treatment of common illnesses among Luo schoolchildren in western Kenya. Soc Sci Med. 2000;50(12):1771-83.

35. Olisa NS, Oyelola FT. Evaluation of use of herbal medicines among ambulatory hypertensive patients attending a secondary health care facility in Nigeria. Int J Pharm Pract. 2009;17(2):101-5.

36. Aboyade O, Beauclair R, Mbamalu O, Puoane T, Hughes GD. Health-seeking behaviours of older black women living with non-communicable diseases in an urban township in South Africa. BMC Complement Altern Med. 2016; 16(1):410.

37. Ching SM, Zakaria ZA, Paimin F, Jalalian M. Complementary alternative medicine use among patients with type 2 diabetes mellitus in the primary care setting: a cross-sectional study in Malaysia. BMC Complement Altern Med. 2013;13(1):148.

38. Cohen RJ, Ek K, Pan CX. Complementary and alternative medicine (CAM) use by older adults: a comparison of self-report and physician chart documentation. J Gerontol A Biol Sci Med Sci. 2002;57(4):M223-M7.

39. Hy C, Wallis M, Tiralongo E. Use of complementary and alternative medicine among people living with diabetes: literature review. J Adv Nurs. 2007;58(4): 307-19.

40. Sharma D, Mazta SR, Parashar A. Morbidity pattern and health-seeking behavior of aged population residing in Shimla Hills of North India: A crosssectional study. J Family Med Prim Care. 2013;2(2):188.

41. Lago S, Cantarero D, Rivera B, Pascual M, Blázquez-Fernández C, Casal B, et al. Socioeconomic status, health inequalities and non-communicable diseases: a systematic review. J Public Health. 2018;26(1):1-14.

\section{Publisher's Note}

Springer Nature remains neutral with regard to jurisdictional claims in published maps and institutional affiliations.

\section{Ready to submit your research? Choose BMC and benefit from:}

- fast, convenient online submission

- thorough peer review by experienced researchers in your field

- rapid publication on acceptance

- support for research data, including large and complex data types

- gold Open Access which fosters wider collaboration and increased citations

- maximum visibility for your research: over $100 \mathrm{M}$ website views per year

At BMC, research is always in progress.

Learn more biomedcentral.com/submissions 